\title{
Peertechz
}

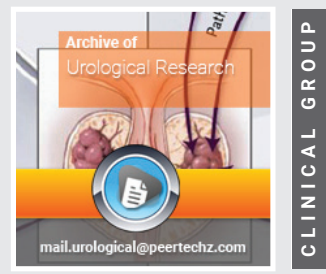

\section{The use of flexible}

\section{ureteroscopy is required to}

improve stone-free rates in ureteroscopy for proximal

\section{ureteral stones}

\section{Fatih Bıçaklıoğlu , Murat Yavuz Koparal2^ and Ender Cem \\ Bulut $^{3}$}

1Urology Clinic, Izmit Seka State Hospital, Kocaeli, Turkey

2Department of Urology, Recep Tayyip Erdogan University Training and Research Hospital, Rize, Turkey

${ }^{3}$ Department of Urology, Van Training and Research Hospital, Van, Turkey

\section{Abstract}

Introduction: The main target in the treatment of proximal ureteral stones (PUS) is to provide a high stone-free rate (SFR) with low morbidity. In this study, we aimed to evaluate the need for flexible ureteroscopy (URS) by retrospectively examining one surgeon's two-year experience of URS for PUS in a center where the flexible ureteroscope and holmium laser lithotriptor are available.

Patients and methods: The medical records of all patients who underwent URS due to PUS by a single surgeon from November 2016 to November 2018 were evaluated retrospectively. Success was accepted as patient with no stones or clinically insignificant residual fragments $\left(<4\right.$ mm) observed at postoperative $4^{\text {th }}$ and $8^{\text {th }}$ weeks by radiological investigation.

Results: URS was performed for PUS in 49 renal units of 48 patients. The mean age was $41.5 \pm 12$. The operation was completed with pure semirigid URS without the use of flexible URS in 13 (26.5\%) RUs. Even in stones with a distance of $>5 \mathrm{~cm}$ to UPJ, two of nine stones required the use of flexible URS. 34 of 40 stones with a distance of $<5 \mathrm{~cm}$ to UPJ required the use of flexible URS. 24 of 26 stones with a distance of $<3 \mathrm{~cm}$ to UPJ required the use of flexible URS. Overall success rates were $100 \%$ ( $38 / 38$ ) for pure PUS and $93.9 \%(46 / 49)$ for PUS with ipsilateral renal stones.

Conclusion: URS is a safe and successful treatment in PUSs. As we have shown in our data, if we want to achieve high SFR with low comorbidity, we should always have flexible URS in the operating room and should use it if necessary.

\section{Introduction}

The main target in the treatment of Proximal Ureteral Stones (PUS) is to provide a high Stone-Free Rate (SFR) with low morbidity. There are now many treatment options for PUS as the result of the development of endourological techniques. These are Extracorporeal Shock Wave Lithotripsy (ESWL), Ureteroscopy (URS) (semirigid-flexible, retrogradeantegrade), Percutaneous Nephrolithotomy (PNL), laparoscopic ureterolithotomy, and open surgery. Today, percutaneous antegrade URS, laparoscopic ureterolithotomy, and open surgery provide a high SFR when used in a small number of special cases, while ESWL and URS constitute the standard treatment of PUS [1]. URS, which has the highest SFR in the treatment of PUS with the development of flexible ureteroscopes, is the first treatment option for stones $>10 \mathrm{~mm}$ and is also the first treatment option with ESWL in stones $<10 \mathrm{~mm} \mathrm{[2].} \mathrm{However,}$ in developing countries, the flexible ureteroscope and holmium 
laser lithotriptor are not used due to their high costs, and the PUS may still have to be treated with a semirigid ureteroscope and pneumatic lithotriptor [3]. In this study, we aimed to evaluate the need for flexible URS by retrospectively examining one surgeon's two-year experience of URS for PUS in a center where the flexible ureteroscope and holmium laser lithotriptor are available. However, the flexible ureteroscope is not used in all PUS cases in order to extend the lifetime of the flexible ureteroscope due to economic considerations. We wanted to examine the SFR under these conditions.

\section{Patients and methods}

The medical records of all patients (48 patients, 49 renal units [RUs]) who underwent URS due to PUS by a single surgeon from November 2016 to November 2018 were evaluated retrospectively. The proximal ureter was defined as the part of the ureter between the Ureteropelvic Junction (UPJ) and the upper border of the sacroiliac joint. No specific exclusion criteria were applied.

All patients had a detailed medical history, physical examination, and laboratory tests, including renal function, complete urinalysis, and urine culture. All patients had Computed Tomography (CT) with stone protocol and plain $\mathrm{X}$-ray of the Kidneys, Ureter and Bladder (KUB) on the morning of the operation. The location of the stone in all patients (as a distance from the UPJ), stone size, and the number of stones were recorded. In the postoperative period, all patients had a KUB on postoperative day one. Patients who had radiopaque stones had KUB and Ultrasonography (USG), and those who had radiolucent stones had CT in postoperative week 4. Patients who continued their follow-up for residual stones had USG in postoperative week8.

Success was accepted as patient with no stones or clinically insignificant residual fragments $(<4 \mathrm{~mm})$ observed at postoperative $4^{\text {th }}$ and $8^{\text {th }}$ weeks by radiological investigation. The size of the stones was taken as the longest axis on the CT. In the patients with postoperative residual fragments, the longest size in KUB was taken for radiopaque stones, and the longest axis in CT was taken for radiolucent stones.

The operation technique was as follows. All patients underwent surgery under general anesthesia in the lithotomy position. One gr of ceftriaxone was given as preoperative antibiotic prophylaxis. Additionally, 6.0/7.5 French (Fr) (Richard Wolf, Germany) and 9.5 Fr (Karl Storz, Germany) were used as the semirigid URS. Flex-X2 (Karl Storz, Germany) was used as the flexible URS. In all patients, a semirigid ureteroscope was inserted into the ureter through a guidewire. At this stage, the patients with a narrow ureteral orifice were not entered and 4.7 Fr D/J catheters were placed, and the stone intervention was postponed after 3-4 weeks. In patients whose stone could be reached with semirigid URS, lithotripsy was performed with 30W holmium:YAG laser lithotriptor (Richard Wolf). The use of an anti-retropulsion device (stone cone or basket) was decided at the case level during the operation. Clinically significant stone fragments were extracted. At the end of the operation, 4.7 Fr D/J or $5 \mathrm{Fr}$ ureter catheters were placed, or no catheter was placed at the case level. We used flexible URS in the following cases: when we went to UPJ with semirigid URS and did not see the stone because of push back to the kidney; when the stone or a significant fragment was pushed back to the kidney while performing lithotripsy with semirigid URS; when we could not reach the stone with semirigid URS due to ureteric kink, or if we reached the stone and we could not perform lithotripsy suitable for the stone due to the angle in the ureter; and in cases with ipsilateral kidney stones. The 9.5-11.5 Fr or 11-13 Fr ureteral access sheaths were used in patients when ureter calibration allowed. In the other patients, lithotripsy was performed with $30 \mathrm{~W}$ holmium:YAG laser lithotriptor (Richard Wolf) by entering sheathless into the renal collecting system with flexible URS via guidewire. Stone extraction was not performed in cases with flexible URS. A 272 $\mu \mathrm{m}$ laser fiber for flexible URS and a $550 \mu \mathrm{m}$ laser fiber for semirigid URS with an energy output of $0.5-1.2 \mathrm{~J}$ at $8-15 \mathrm{~Hz}$ was used; but the $\mathrm{J}$ and $\mathrm{Hz}$ of energy could be changed during the operation according to the stone hardness and efficacy of lithotripsy. A 4.7 Fr D/J catheter was inserted in all patients who were operated with flexible URS.

A statistical analysis was performed. In this study, continuous variables were shown as mean \pm Standard Deviation (SD). Categorical variables were shown as percentages. For the statistical analysis, Statistical Package for the Social Sciences version 15.0 (SPSS Chicago, Il, USA) was used.

\section{Results}

Patient and stone characteristics of 49 RUs are detailed in Table 1.

Table 1: Patient and stone characteristics.

\begin{tabular}{|c|c|}
\hline Patients $(\mathrm{n})$ & 48 \\
\hline Renal Unit $(\mathrm{n})$ & 49 \\
\hline Age (years) $($ mean \pm SD) & $41.5 \pm 12$ \\
\hline Serum creatinine $(\mathrm{mg} / \mathrm{dl})(\mathrm{mean} \pm \mathrm{SD})$ & $1.03 \pm 0.24$ \\
\hline Gender $[\mathrm{n}(\%)]$ & \\
\hline Female & $18(37.5)$ \\
\hline Male & $30(62.5)$ \\
\hline Side [n (\%)] & \\
\hline Right & $25(52)$ \\
\hline Left & $22(46)$ \\
\hline Bilateral & $1(2)$ \\
\hline Stone radiopacity $[\mathrm{n}(\%)]$ & $41(83.7)$ \\
\hline Radiopaque & $8(16.3)$ \\
\hline Radiolucent & \\
\hline Hydronephrosis $[\mathrm{n}(\%)]$ & $4(8.2)$ \\
\hline Grade 0 & $18(36.7)$ \\
\hline Grade 1 & $19(38.8)$ \\
\hline Grade 2 & $8(16.3)$ \\
\hline Grade 3 & $32 \pm 22$ \\
\hline Distance from UPJ (mean $\pm \mathrm{SD})(\mathrm{mm})$ & $10.9 \pm 4$ \\
\hline Length of stone (mean $\pm \mathrm{SD})(\mathrm{mm})$ & \\
\hline
\end{tabular}

Abbreviations: SD: Standard Deviation

Citation: Bıçaklıoğlu F, Koparal MY, Bulut EC (2021) The use of flexible ureteroscopy is required to improve stone-free rates in ureteroscopy for proximal ureteral 
Thirty-three $(67.3 \%)$ RUs were referred to us by other urologists because of the necessity to use flexible URS. Three (6.1\%) RUs had more than one PUS (two in two RUs, and three in one RU). Eleven (22.4\%) RUs had ipsilateral renal calculi with PUS. Seven RUs (14.3\%) underwent ESWL at another hospital that had an ESWL unit in the preoperative period but these failed. Two (4.1\%) RUs had failed semirigid URS in the external unit and were referred to us because of the lack of flexible URS. Three $(6.1 \%)$ RUs had D/J catheters inserted prior to ureteroscopy. $\mathrm{A} \mathrm{D/J}$ catheter was inserted in two of them due to narrow ureter and in one due to lack of anesthesia because of thyroid dysfunction.

Ureteral stone distance from UPJ and usage of flexible URS summarized in Table 2. Even in stones with a distance of $>5 \mathrm{~cm}$ to UPJ, two of nine stones required the use of flexible URS. 34 of 40 stones with a distance of $<5 \mathrm{~cm}$ to UPJ required the use of flexible URS. 24 of 26 stones with a distance of $<3 \mathrm{~cm}$ to UPJ required the use of flexible URS.

In $24(49 \%)$ RUs operated with flexible URS (including 11 RUs with ipsilateral kidney stones ), the lithotripsy was performed in the renal collecting system because of push back. In seven (14.3\%) RUs operated with flexible URS, lithotripsy was initiated in the ureter with semirigid URS, but the lithotripsy was continued in the renal collecting system due to the stone or large fragments push back to the kidney. In three $(6.1 \%)$ RUs operated with flexible URS, lithotripsy was initiated in the ureter with flexible URS, but the lithotripsy was continued in the renal collecting system because significant fragments were pushed back to the kidney. In two (4.1\%) RUs operated with flexible URS, lithotripsy was performed in the ureter with flexible URS. A basket was used in only one $(2 \%)$ patient (the first patient of the series) as a retropulsion device, but we did not use it again because we thought that its use at this level may cause serious ureteral complications such as ureteral perforation or uretral avulsion because of our inexperience with basket. Stone Cone (Boston Scientific Corp, Natick, MA, USA) was used in 12 RUs. Of these, 10 RUs were operated on only with semirigid URS. In two RUs that the Stone Cone was used in, significant fragments were pushed back to the kidney, and we used flexible URS. A ureteral access sheath was used in $20(40.8 \%)$ RUs. In nine (18.4\%) RUs, stones were anklave, and we used flexible URS in seven of these. We think that the possible cause of this is increased irrigation fluid pressure for a better view in anklave stones that, surrounded by mucosal edema and fragments, were pushed back with increased pressure because we could not pass the Stone Cone to proximal of anklave stones. D/J catheter was placed in 44 (89.8) RUs, and a ureter catheter was placed in four $(8.2 \%)$ RUs. A catheter was not placed in one $(2 \%)$ RU. In six $(12.2 \%)$ RUs, simultaneous operation was performed on the contralateral RU (URS for two and RIRS for four).

Table 3 detailed gradual changes in success rates of ureteroscopy in postoperative 8 weeks. At the end of 8 weeks, overall success rates were $100 \%(38 / 38)$ for proximal ureter stones and $93.9 \%(46 / 49)$ for all stones.
Table 2: Stone distance from ureteropelvic junction and pure semirigid-flexible URS usage.

\begin{tabular}{|c|c|c|c|c|}
\hline -URS type & -Stone distance & $>5 \mathrm{~cm}$ to UPJ & $<5 \mathrm{~cm}$ to UPJ & $<3 \mathrm{~cm}$ to UPJ \\
\hline \multirow{2}{*}{ ure Semirig } & & $7(\% 14,2)$ & $6(\% 12,2)$ & $2(\% 4,2)$ \\
\hline & & $2(\% 4,2)$ & $34(\% 69,3)$ & $24(\% 48,9) 36(\% 73,5)$ \\
\hline Flexible* & & $9(\% 14,8)$ & $40(\% 81,6)$ & $26(\% 53,1)$ \\
\hline
\end{tabular}

Table 3: Success rates of ureteroscopy at the end of postoperative 8 weeks.

\begin{tabular}{|c|c|c|c|c|}
\hline & & Day 1 & Week 4 & Week 8 \\
\hline \multirow{4}{*}{$\begin{array}{l}\text { PUS with ipsilateral } \\
\text { renal stones }\end{array}$} & Successful & $43(87.7)$ & $46(93.9)$ & $46(93.9)$ \\
\hline & Stone free & $33(67.3)$ & $42(85.8)$ & $45(91.9)$ \\
\hline & $\begin{array}{l}\text { Clinically insignificant } \\
\text { residual fragment }\end{array}$ & $10(20.4)$ & $4(8.1)$ & $1(2.0)$ \\
\hline & $\begin{array}{c}\text { Failed / Significant residual } \\
\text { fragment }\end{array}$ & $6(12.3)$ & $3(6.1)$ & $3(6.1)$ \\
\hline \multirow{4}{*}{ Pure PUS } & Successful & $37(97.3)$ & $38(100)$ & $38(100)$ \\
\hline & Stone free & $31(81.6)$ & $36(94.8)$ & $37(97.4)$ \\
\hline & $\begin{array}{l}\text { Clinically insignificant } \\
\text { residual fragment }\end{array}$ & $6(15.7)$ & $2(5.2)$ & $1(2.6)$ \\
\hline & $\begin{array}{c}\text { Failed / Significant residual } \\
\text { fragment }\end{array}$ & $1(2.6)$ & 0 & 0 \\
\hline
\end{tabular}

Abbreviations: PUS: Proximal Ureteral Stone

The hospital stay was median 1.6 (1-16) days. In total, 43 RUs were hospitalized for one day. One patient with preoperative severe urinary infection and two patients with postoperative urinary infection were hospitalized longer. $\mathrm{D} / \mathrm{J}$ catheters were taken out after median 33.8 (19-84) days. Only one patient, the one with recurrent ureteral stricture, required additional intervention. We performed a laser endoscopic ureterotomy on this patient.

Complications occurred in nine $(18.3 \%)$ RUs. Of these, six had mild hematuria (Clavien grade 1) that was treated conservatively. Two had postoperative urinary infection (Clavien grade 2). They consulted to infectious diseases and treated with antibiotics (no need for intensive care). One patient had ureteric stenosis, and balloon dilatation was performed. She had a $4 \mathrm{~mm}$ residual fragment at the stricture site in postoperative $4^{\text {th }}$ week KUB and $8^{\text {th }}$ week CT. Even though we kept the $\mathrm{D} / \mathrm{J}$ catheter in this patient for 84 days, a more severe recurrent ureteral stricture (Clavien grade $3 \mathrm{~b}$ ) occurred. We performed a laser endoscopic ureterotomy for this patient and $\mathrm{D} / \mathrm{J}$ catheter was taken out after 45 days. There was no obstruction in postoperative $3^{\text {rd }}$ month DTPA scintigraphy and stone free in postoperative KUB and USG.

\section{Discussion}

Currently, URS is the first treatment option in PUS, according to European Association of Urology (EAU) guidelines, but we must inform our patients that ESWL is a treatment alternative in stones $<10 \mathrm{~mm}[2]$. We informed the appropriate patients that ESWL is a treatment alternative for them. In addition, we gave information about ESWL to patients who had $>10 \mathrm{~mm}$ PUS and refused to go URS. We referred our patients who chose ESWL to another urology clinic because there is no ESWL unit at our clinic. We do not know the success of ESWL in these patients because no follow-up was available to us.

Of course, these recommendations suggest that URS is 
recommended in all PUS, but it should be noted that this is a URS procedure including flexible ureteroscopes that have a small diameter and active deflection $[4,5]$. However, the cost of flexible ureteroscopes and holmium lasers for lithotripsy is very high, and these devices are not always available in developing countries [3]. In a study by Khairy-Hair, et al. they included patients who had 10-20 mm PUS. The SFR was $90.6 \%$ in postoperative week 2 and $98.6 \%$ in postoperative month 3 with semirigid URS and pneumatic lithotripsy [3]. In the Clinical Research Office of the Endourological Society (CROES) Ureteroscopy Study Group, 2656 RUs that underwent URS for PUS were evaluated. In URS for PUS, semirigid URS was used in $72.1 \%$ of the RUs, flexible URS was used in $11.2 \%$, and both were used in $16.4 \%$. In lithotripsy, holmium laser was used in $60.8 \%$ of the RUs, pneumatic was used in $27.5 \%$, electrohydraulic, ultrasonic, or various combinations were used in the others. The SFR was $84.5 \%$ [6]. In their experience with semirigid URS and pneumatic lithotripsy, Yencilek, et al. achieved a success rate of $71.7 \%$ in the PUSs (7). In our study, we used semirigid URS, flexible URS (when necessary), and holmium laser (in all lithotripsies). Our SFR was $93.9 \%$. When we excluded patients with ipsilateral kidney stones, our SFR was $100 \%$. At this point, we were able to obtain a significant SFR difference when compared to the studies of the CROES ureteroscopy group (that most often used semirigid URS) and Yencilek, et al. (who only used semirigid URS) $[6,7]$. Interestingly, in the KhairyHair, et al. study (who only used semirigid URS), they had an SFR of $98.6 \%$. Higher SFRs may be obtained with semirigid URS in more experienced centers; however, a SFR of $98.6 \%$ seems to be exaggerated. Comparative analysis studies seem to make more sense in comparing flexible URS and semirigid URS success. In the retrospective study of Karadag, et al. the SFRs were $93.4 \%$ in the flexible URS group and $77.7 \%$ in the semirigid URS group [8]. In the study by Galal, et al. the SFRs were $68 \%$ in the rigid URS group and $91 \%$ in the flexible URS group, and in the study by Alkan, et al. the SFRs were $76.5 \%$ in the rigid URS group and $87.5 \%$ in the flexible URS group $[9,10]$. In a multicenter prospective study by Hyams, et al. the SFR was $95 \%$ for PUS $<2 \mathrm{~cm}$ operated with flexible URS. Again, in this study, the SFR was $100 \%$ for PUS $<1 \mathrm{~cm}$ [11]. At this point, our SFR seems to be compatible with the literature. In our series, we started lithotripsies with semirigid URS in 20 (41.3\%) RUs. In $13(27 \%)$ of them, we were able to obtain a stone-free condition only with semirigid URS; in 7 (14.3\%) of them, we continued lithotripsies in the renal collecting system with flexible URS because fragments were pushed back to the kidney. Even if we did not have flexible URS in these patients and would expect the stone fragments, which were pushed back, to spontaneous passage in the follow-up in most of them, we would have accomplished approximately a $40 \%$ SFR with semirigid URS. Even the SFR, which may occur by considering the best possibilities, appears to be far below the success rates of semirigid URS in the literature [7-10]. We think that this is related to the number of patients referred to us from other clinics (33 RUs, 67.3\%) who may require flexible URS because of the fact that it is close to the UPJ in our series. Forty ( $81.6 \%)$ of the RUs in our series were $<5 \mathrm{~cm}$ to the UPJ, and 26 (53.1\%) were $<3 \mathrm{~cm}$ to the UPJ. In clinics referring these patients, they operated the proximal ureteral stones that were far from UPJ (less likely to push back to the kidney) with only semirigid URS. In addition, we could not see the medical records of these patients, so it was not possible to know how successful we would be using semirigid URS in PUS.

In some series, and perhaps even in our series, the highest SFRs seem to be related to the radiological evaluations we used for postoperative residual stone evaluation. There is a significant difference among investigating residual stones with KUB, USG, or CT $[12,13]$. However, in clinical practice, a new CT scan is often not possible due to avoiding the use of radiation on our patients who had CT in the preoperative period. If we could have evaluated all the patients with $\mathrm{CT}$ in the postoperative period, our SFR would probably have decreased, and the number of the RUs with significant or insignificant residual fragments would have increased. In a study conducted by the Endourology Disease Group for Excellence (EDGE) Research Consortium, in patients with $<4 \mathrm{~mm}$ CIRFs which we included in the stone-free group, a re-intervention was required in $18 \%$ of the follow-ups, and the same was found for $19.6 \%$ in the study of Rebuck, et al. $[14,15]$. At this point, it is not entirely possible to say that we are fully successful in patients with residual fragments (even if they are CIRFs). In our study, it may be thought that because we did not do the stone extraction with a basket in the RUs and used flexible URS, this may have caused residual fragments, but in the study of the EDGE Research Consortium comparing dusting with basketing, the SFR in multivariate analysis was similar, and there was no significant difference in the number of patients who became symptomatic due to residual fragments in this study. However, the mean duration of surgery in the basketing group increased by 37.7 minutes [16]. We do not use baskets with flexible URS for stone extraction in our clinic.

In terms of complications, six $(12.3 \%)$ patients had hematuria (Clavien grade 1 ) that was treated with conservative follow-up, two $(4.1 \%)$ patients had urinary infection (Clavien grade 2) that was treated with postoperative hospitalization and antibiotic treatment, and one patient had recurrent ureteral stricture (Clavien grade $3 \mathrm{~b}$ ) that was treated with surgical intervention (laser endoscopic ureterotomy). None of our patients had Clavien grades 4 and 5 complications [17]. In most of the other studies, ureteral stricture was an exclusion criteria, so we did not see any recurrent ureteral strictures in these series [3,7,9-11]. In the CROES Ureteroscopy Study Group, $0.9 \%$ of their patients had ureteral stricture after ureteroscopy for PUS [6]. In the study of Hyams, et al. three (4.3\%) patients had postoperative urinary infection after flexible URS for PUS, and two $(4.1 \%)$ of our patients had postoperative urinary infection. In the study of Alkan, et al. ureteral perforation was seen in one patient, ureteral avulsion was seen in one patient in the semirigid URS group, and patients did not have these complications in the flexible URS group [10]. We did not see these two most frightening complications of ureteroscopy in our series; we think that the reason for this is we did not force patients to be operated with only semirigid URS and switched to flexible URS if necessary. Our complication rate seems to be compatible with the literature.

Citation: Bıçaklıoğlu F, Koparal MY, Bulut EC (2021) The use of flexible ureteroscopy is required to improve stone-free rates in ureteroscopy for proximal uretera 


\section{Conclusion}

URS is a safe and successful treatment in PUSs. As we have shown in our data, if we want to achieve high SFR with low comorbidity, we should always have flexible URS in the operating room and should use it if necessary. Otherwise, it seems reasonable to refer patients to a nearby center that does have flexible URS.

\section{References}

1. Preminger GM, Tiselius HG, Assimos DG, Alken $P$, Colin Buck A, Gallucci $M$, et al. (2007) Guideline for the Management of Ureteral Calculi. Eur Urol 52: 16101631. Link: https://bit.ly/3bRibEF

2. Türk C, Petř́k A, Sarica K, Seitz C, Skolarikos A, et al. (2016) EAU Guidelines on Diagnosis and Conservative Management of Urolithiasis. Eur Urol 69: 468-474. Link: https://bit.ly/3qxbOuf

3. Khairy-Salem H, El Ghoneimy M, El Atrebi M (2011) Semirigid Ureteroscopy in Management of Large Proximal Ureteral Calculi: Is There Still a Role in Developing Countries? Urology 77: 1064-1068. Link: https://bit.ly/35U1Gnp

4. Grasso M, Bagley D (1998) Small diameter, actively deflectable, flexible ureteropyeloscopy. J Urol 11: 1648-1153. Link: https://bit.ly/3nZiGyV

5. Leone NT, Garcia-Roig M, Bagley DH (2010) Changing Trends in the Use of Ureteroscopic Instruments from 1996 to 2008. J Endourol 24: 361-365. Link: https://bit.ly/3p1wZEC

6. Perez Castro E, Osther PJS, Jinga V, Razvi H, Stravodimos KG, et al. (2014) Differences in Ureteroscopic Stone Treatment and Outcomes for Distal, Mid-, Proximal, or Multiple Ureteral Locations: The Clinical Research Office of the Endourological Society Ureteroscopy Global Study. Eur Urol 66: 102-109. Link: https://bit.ly/2XSsS1z

7. Yencilek F, Sarica K, Erturhan S, Yagci F, Erbagci A (2010) Treatment of Ureteral Calculi with Semirigid Ureteroscopy: Where Should We Stop? Urol Int 84: 260-264. Link: https://bit.ly/3irnETS

8. Cecen K, Karadag MA, Demir A, Bagcioglu M, Kocaaslan R, et al. (2014) Flexible
Ureterorenoscopy versus Extracorporeal Shock Wave Lithotripsy for the treatment of upper/middle calyx kidney stones of $10-20 \mathrm{~mm}$ : a retrospective analysis of 174 patients. SpringerPlus 3: 557. Link: https://bit.ly/3sAkcuN

9. Galal EM, Anwar AZ, El-Bab TKF, Abdelhamid AM (2016) Retrospective comparative study of rigid and flexible ureteroscopy for treatment of proximal ureteral stones. Int Braz J Urol 42: 967-972. Link: https://bit.ly/3nX9xqv

10. Alkan E, Sarıbacak A, Ozkanli AO, Basar MM, Acar O, et al. (2015) Flexible Ureteroscopy Can Be More Efficacious in the Treatment of Proximal Ureteral Stones in Select Patients. Adv Urol 2015: 416031. Link: https://bit.ly/3ioMfZw

11. Hyams ES, Monga M, Pearle MS, Antonelli JA, Semins MJ, et al. (2015) A Prospective, Multi-Institutional Study of Flexible Ureteroscopy for Proximal Ureteral Stones Smaller than $2 \mathrm{~cm}$. J Urol 193: 165-169. Link: https://bit.ly/3io9nHI

12. Park J, Hong B, Park T, Park HK (2007) Effectiveness of Noncontrast Computed Tomography in Evaluation of Residual Stones after Percutaneous Nephrolithotomy. J Endourol 21: 684-687. Link: https://bit.ly/3qsCDzC

13. Gokce MI, Ozden E, Suer E, Gulpinar B, Gulpınar O, et al. (2015) Comparison of imaging modalities for detection of residual fragments and prediction of stone related events following percutaneous nephrolitotomy. Int Braz J Urol 41: 8690. Link: https://bit.ly/3oZuFh4

14. Chew BH, Brotherhood HL, Sur RL, Wang AQ, Knudsen BE, et al. (2016) Natura History, Complications and Re-Intervention Rates of Asymptomatic Residual Stone Fragments after Ureteroscopy: a Report from the EDGE Research Consortium. J Urol 195: 982-986. Link: https://bit.ly/35Sbxu5

15. Rebuck DA, Macejko A, Bhalani V, Ramos P, Nadler RB (2011) The Natura History of Renal Stone Fragments Following Ureteroscopy. Urology 77: 564 568. Link: https://bit.ly/3bPnswn

16. Humphreys MR, Shah OD, Monga M, Chang YH, Krambeck AE, et al. (2018) Dusting versus Basketing during Ureteroscopy-Which Technique is More Efficacious? A Prospective Multicenter Trial from the EDGE Research Consortium. J Urol 199: 1272-1276. Link: https://bit.ly/3bSvODq

17. Dindo D, Demartines N, Clavien PA (2004) Classification of Surgical Complications. Ann Surg 240: 205-213. Link: https://bit.ly/3sFJWWA

Discover a bigger Impact and Visibility of your article publication with

Peertechz Publications

Highlights

* Signatory publisher of ORCID

* Signatory Publisher of DORA (San Francisco Declaration on Research Assessment)

- Articles archived in worlds' renowned service providers such as Portico, CNKI, AGRIS, TDNet, Base (Bielefeld University Library), CrossRef, Scilit, J-Gate etc.

* Journals indexed in ICMJE, SHERPA/ROMEO, Google Scholar etc.

* OAI-PMH (Open Archives Initiative Protocol for Metadata Harvesting)

* Dedicated Editorial Board for every journal

* Accurate and rapid peer-review process

* Increased citations of published articles through promotions

* Reduced timeline for article publication

Submit your articles and experience a new surge in publication services (https://www.peertechz.com/submission).

Peertechz journals wishes everlasting success in your every endeavours.

Copyright: () 2021 Bıçaklığlu F, et al. This is an open-access article distributed under the terms of the Creative Commons Attribution License, which permits unrestricted use, distribution, and reproduction in any medium, provided the original author and source are credited.

Citation: Bıçaklıoğlu F, Koparal MY, Bulut EC (2021) The use of flexible ureteroscopy is required to improve stone-free rates in ureteroscopy for proximal ureteral stones. Arch Urol Res 5(1): 001-005. DOI: https://dx.doi.org/10.17352/aur.000028 